\title{
Do farming practices influence population dynamics of rodents? A case study of the multimammate field rats, Mastomys natalensis, in Tanzania
}

\author{
A. W. Massawe ${ }^{1 *}$, W. Rwamugira ${ }^{2}$, H. Leirs ${ }^{3,4}$, R. H. Makundi ${ }^{1}$ and \\ Loth S. Mulungu ${ }^{1}$ \\ ${ }^{1}$ Pest Management Centre, Sokoine University of Agriculture, PO Box 3110, Morogoro, Tanzania, ${ }^{2}$ Crop Science and Production, Sokoine \\ University of Agriculture, PO Box 3005, Morogoro, Tanzania, ${ }^{3}$ University of Antwerp, Antwerp, Groenenborgeelan 171, B-2020, Belgium, and \\ ${ }^{4}$ Danish Pest Infestation Laboratory, Kgs. Lyngby, Denmark
}

\begin{abstract}
A capture-mark-recapture study was conducted in crop fields in Morogoro, Tanzania, to investigate how the population dynamics of multimammate field rats, Mastomys natalensis, was influenced by the commonly practised land preparation methods and cropping systems. Two land preparation methods (tractor ploughing and slash and burn) and two cropping systems (mono-cropping with maize and inter-cropping with maize and beans) were investigated in a Complete Randomized Design experiment with $2 \times 2$ factors, and two 0.5 ha replicates per treatment. Mastomys natalensis comprised $97.8 \%$ of the abundance of the three rodent species captured in the study area. The slash and burned fields had higher rodent population densities than tractor ploughed fields $(P<0.05)$. Recruitment rates were higher in the slash and burn fields than in the tractor ploughed fields, suggesting that the former were more favourable habitats for M. natalensis. Land preparation methods appeared to influence the population dynamics of M. natalensis through recruitment of new individuals in the population and most probably survival. Apart from the temporal changes in population density, which were reflected in both tractor ploughed and slash and burn fields, cropping systems (mono- and inter-crop) had little effect on the population dynamics of $M$. natalensis $[F(1,8)=6.50$; $P>0.05]$. The study shows that land preparation methods should be considered a component of rodent pest management in ecologically based or integrated management practices. In maize fields in Tanzania, the crop is most susceptible to damage by M. natalensis in the first 2 weeks after
\end{abstract}

*Correspondence: Fax: +25523 2601485; E-mail: massawe@ suanet.ac.tz or apiamas@yahoo.com planting, and therefore, lower densities of rodents will result into lower crop damage in tractor ploughed fields.

Key words: land preparation, Mastomys natalensis, population dynamics

\section{Resume}

On a réalisé une étude par capture/marquage/remise en liberté dans des cultures de Morogoro, en Tanzanie, pour savoir comment la dynamique de la population de Mastomys natalensis était influencée par les méthodes de préparation des champs et les systèmes de récoltes habituellement utilisés. Deux méthodes de préparation des sols, le labourage avec tracteur et la culture sur brûlis, et deux systèmes de culture, monoculture de maïs ou culture mixte de maïs et de haricots, ont été étudiés par un Plan d'expérience complètement aléatoire, avec $2 \times 2$ facteurs et deux réplications de 0,5 ha par traitement. En termes d'abondance, Mastomys natalensis représentait 97,8\%, des trois espèces de rongeurs capturés dans la zone d'étude. Les cultures sur brûlis avaient une plus forte densité de population de rongeurs que les champs labourés avec tracteur $(P<0,05)$. Les taux de recrutement étaient plus élevés dans les cultures sur brûlis que dans les champs labourés avec tracteur, ce qui fait supposer que les premières sont des habitats plus favorables pour M. natalensis. Les méthodes de préparation des sols semblaient influencer la dynamique de la population de M. natalensis par le recrutement de nouveaux individus dans la population et très probablement la survie. Mis à part les changements temporels de la densité de population, qui touchaient les cultures sur brûlis et les champs labourés avec tracteur, les systèmes de culture, monoculture ou 
culture mixte, avaient peu d'effets sur la dynamique de la population de $M$. natalensis $(\mathrm{F}(1,8)=6,50 ; P>0,05)$. L'étude montre que les méthodes de préparation des sols devraient être envisagées comme composantes de la lutte contre les rongeurs nuisibles dans les pratiques de gestion écologiques ou intégrées. Dans les champs de maïs, en Tanzanie, la récolte peut être endommagée par les rongeurs au cours des deux premières semaines qui suivent les semis; c'est pourquoi les plus faibles densités de rongeurs observées dans les champs labourés avec tracteur signifient moins de dommages aux cultures.

\section{Introduction}

In developing countries, which are predominantly agrarian, rodent infestation poses a serious threat of not only reduced income but also widespread food shortages (Milan, 1990). Tanzania, like other tropical African countries, has diverse genera and species of rodents, the majority of which are murids (true rats and mice). Periodic outbreaks of some rodent species affecting agricultural crops occur in the country (Makundi, 1999).

Farming practices affect the nature of the habitat, shelter and population density of rodents (Makundi, Oguge \& Mwanjabe, 1999; Massawe et al., 2003). In Tanzania, a mosaic of small plots of various crops, intermingled with patches of fallow and permanent grassland, combined with minimum land preparation (slash and burning practices) and subsequent flourishing of weeds, create favourable conditions for species, including M. natalensis (Taylor, 1968; Myllymäki, 1989; Mwanjabe, 1993).

An understanding of the factors that influence the population dynamics of rodent pests and the way in which cropping systems differ from natural ecosystems, can provide an indication of the type of strategies that should be employed to supplement conventional rodent management practices. We can achieve management of rodent pests in a crop system if the techniques used not only reduce both the initial numbers infesting the crop and the rate of population growth, but also create an environment that reduces recruitment and survival. Therefore, optimal management strategies can only be determined with reference to the ecology of the rodent pest and its interactions with the crop management components. The current study was conducted to investigate how different land preparation methods and cropping systems affect population charac- teristics of rodents in the field, and whether they influence population dynamics.

\section{Materials and methods}

The study area was located at Solomon Mahlangu Campus (Mazimbu) $\left(6^{\circ} 46^{\prime} \mathrm{S}, 37^{\circ} 37^{\prime} \mathrm{E}\right)$, Sokoine University of Agriculture, Morogoro, Tanzania. A capture-mark-recapture study was conducted during the 1999-2001 cropping seasons. Eight $70 \times 70 \mathrm{~m}$ grids were prepared, consisting of seven parallel lines, $10 \mathrm{~m}$ apart, and seven trapping stations per line, also $10 \mathrm{~m}$ apart (total of 49 trapping stations/grid). One Sherman LFA live trap (H.B. Sherman Traps Inc., Tallahassee, FL, U.S.A.) was placed on each trapping station. A 200-300 m wide zone of fallow land separated the grids from each other. The grids were subjected to two types of cropping systems (monocropping and inter-cropping) and two land preparation methods (tractor ploughing and slash and burning). The mono-cropping system consisted of a monoculture of maize and the inter-crop consisted of a mixture of maize and beans. The choice of these treatments was based on common farming practices in Tanzania. The experiment was a Complete Randomized Design with $2 \times 2$ factors replicated twice. The treatment plots were as follows: tractor ploughed fields with maize mono-crop (DM1; DM2), slash and burn fields with maize mono-crop (SM3; SM4), tractor ploughed fields with maize intercropped with beans (DI5; DI6), slash and burn fields with maize intercropped with beans (SI7; SI8) (These abbreviations are used throughout this paper to identify the fields.) The grids were ploughed in November and February during the short rainy season and long rainy season, respectively. Tractor ploughing was carried out using a disc plow at a depth of $30 \mathrm{~cm}$, a normal rooting depth for most annual crops. Harrowing was not done, as in most small-scale farming practices, farmers do not harrow their fields. In the slash and burn fields, slashing was done by hand hoe and the weeds were left to dry for 1 or 2 days depending on the weather conditions and thereafter burnt within the fields. Maize sowing followed a standard procedure [planting lines $90 \mathrm{~cm}$ apart, plant holes $60 \mathrm{~cm}$ apart, and three seeds per planting hole (variety Staha)]. The bean crop was sown 3 weeks after the maize, at a spacing of $50 \mathrm{~cm} \times 10 \mathrm{~cm}$ (Variety Kablanket). All necessary agronomic practices such as fertilizer application and weeding were carried out equally in all the plots. Triple Super Phosphate $\left(20 \mathrm{~kg} \mathrm{ha}^{-1}\right)$ and Nitrogen (40 kg $\mathrm{N} \mathrm{ha}^{-1}$ ) 
were applied before sowing and 3-4 weeks after sowing, respectively.

Trapping was conducted in each grid for three consecutive nights at intervals of 4 weeks. Additionally, trapping was conducted for three consecutive nights before land preparation (ploughing or slashing/burning), after land preparation, and after seed emergence. Traps were baited in the afternoon with peanut butter mixed with maize bran and were inspected early in the morning. Toe clipping using specific number coding was used to recognize individual animals. The trapping station, sex, weight and reproductive status of captured animals were recorded. Animals were later released at the station of capture.

Population size was estimated for each 3-day trapping session using the $\mathrm{M}(\mathrm{h})$ estimator of the program CAPTURE for a closed population, which allows for individual variations in trapping probability (White et al., 1982).

Recruitment of new individuals to the population in the different treatments was determined by establishing the proportions of new individuals entering the trappable population during the entire study period and at different stages of crop production (after ploughing, after seed emergence and at vegetative stage in the different seasons). The number of unmarked animals out of the total capture for each trapping session was used to establish the proportion of new recruitment into the population. The proportions of new individuals were compared between treatment combinations, using the Repeated Measure Analysis (GLM procedure in STATISTICA).

\section{Results}

Species composition in the fields

During the study period we captured 2874 individuals out of a total of 36,456 trap nights. The relative proportions in the composition of the different species in the fields during the study period were as follows: Mastomys natalensis $97.8 \%$, Tatera swaythlingi $1.6 \%$ and Mus minutoides $0.4 \%$. Two shrews, Crocidura hirta comprised $0.2 \%$ of the captures.

There were no significant differences $(P \geq 0.05)$ in species composition in fields subjected to the different land preparation methods and cropping systems. Also, there were no interaction effects $(P \geq 0.05)$ of field and time on species composition during the study period.

\section{Population dynamics}

Population density estimates of $M$. natalensis for each treatment are presented in Figs 1-4. In general, population peak was reached during the short rainy season (November-December) and declined in subsequent months during the long rainy season (March-May) in all

Fig 1 Rodent population abundance (Mh estimator of the Program Capture) changes in tractor ploughed fields (mono-crop) (April 1999-July 2001) (arrows show the timing of land preparation)

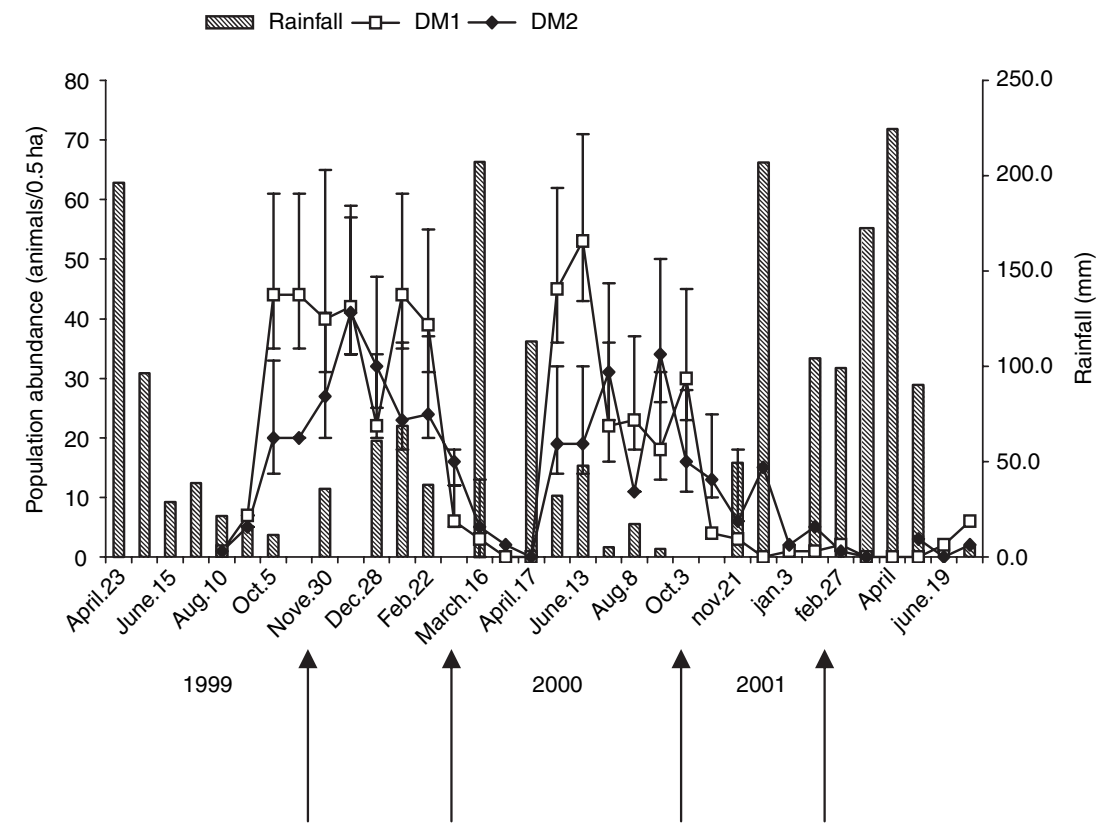




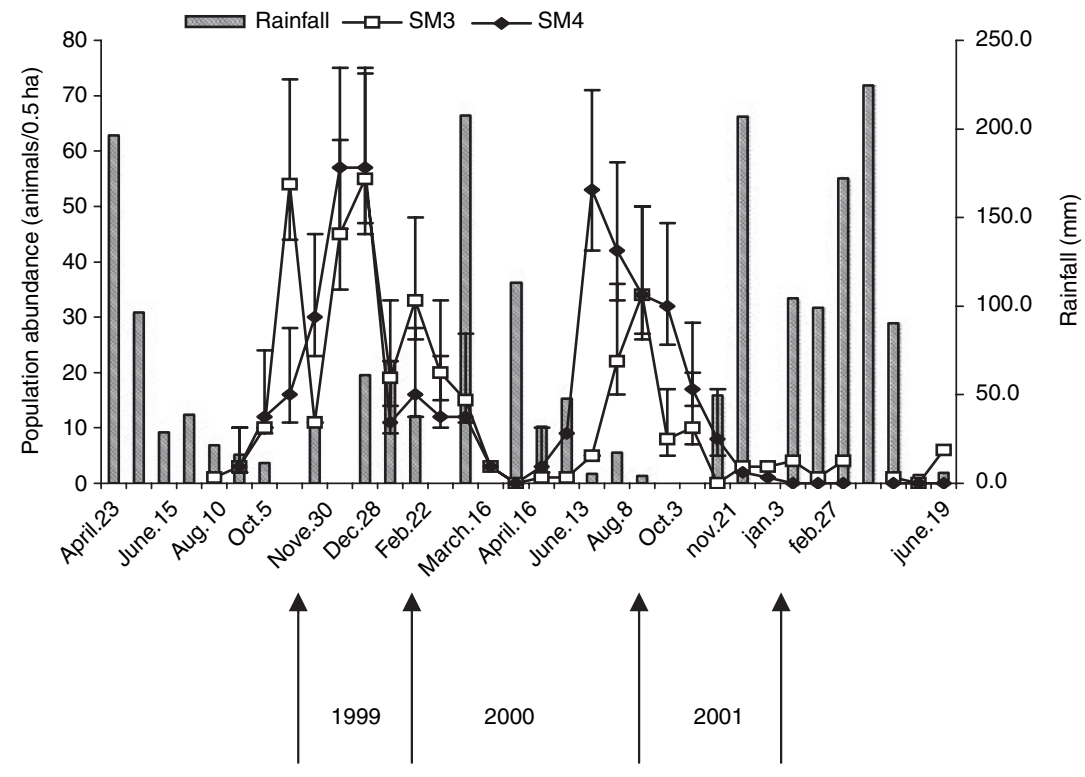

Anam Rainfall $\rightarrow$ D15 $\longrightarrow$ D16
Fig 2 Rodent population abundance (Mh estimator of the Program Capture) changes in slash and burn fields (mono-crop) (April 1999-2001) (arrows show the timing of land preparation)



Fig 3 Rodent population abundance $(\mathrm{Mh}$ estimator of the Program Capture) changes in tractor ploughed fields (inter-crop) (April 1999-July 2001) (arrows show the timing of land preparation)

the treatments. During the short rainy season of 1999 , trapping after land preparation (November 30) resulted in a drop in population density in all the slash and burn fields (Figs 2 and 4). This effect was not so obvious in field SM4 in which burning was incomplete due to the type of vegetation in the field (Commelina spp. and Convolvulacea family were the most abundant in this field during this time of the year). Variations in the population trend were seen between DM1 and DM2 although they were not significant. Population peak was reached earlier in DM1 than in DM2 (Fig. 1).
An increase in the population abundance in all the fields occurred after seed emergence (10 December 1999), but this trend was much more evident in the slash and burn fields. Although very few animals were present in the fields during the long rainy season (March-May 2000), there were more animals captured in the slash and burn fields than in the tractor ploughed fields.

Fluctuations in the population density of M. natalensis occurred in all the fields. The highest density occurred in 1999-2000, but densities were low in 2001. The general trend indicated that rodent population density increased at 
Fig 4 Rodent population abundance (Mh estimator of the Program Capture) changes in slash and burn fields (inter-crop) (April 1999-July 2001) (arrows show the timing of land preparation)

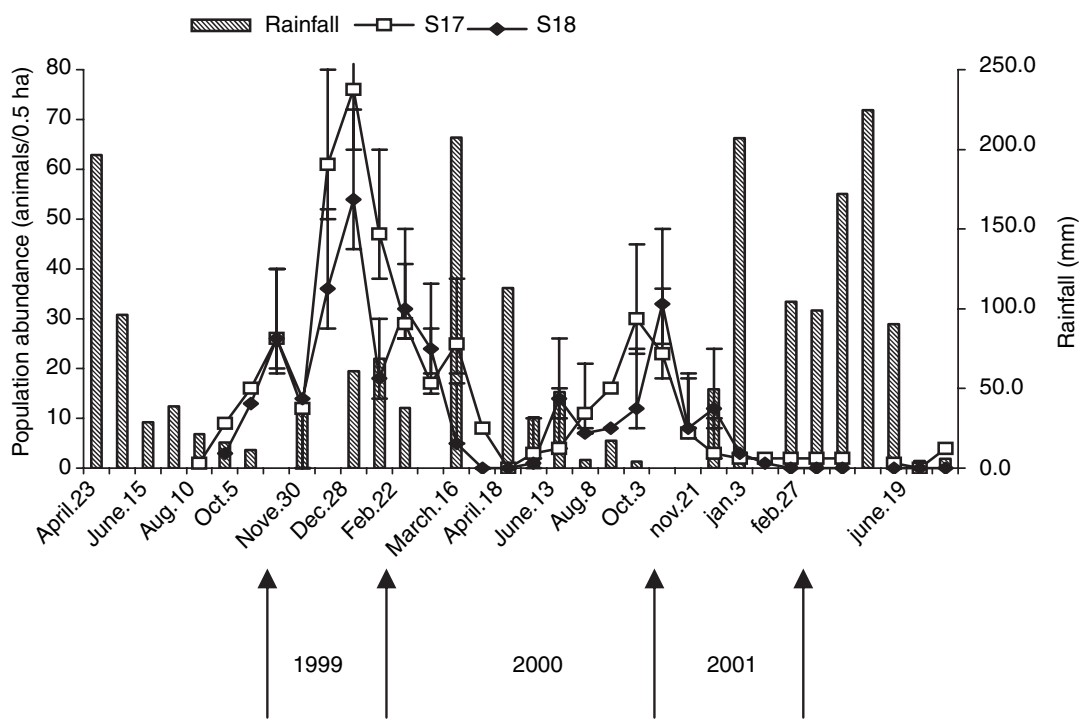

in the slash and burn fields than in the tractor ploughed fields (Tukey HSD test; $P=0.03$; mean numbers of animals/0.5 ha: $14.7 \pm 2.79$ and $9 \pm 1.72$, respectively).

The population peaks differed significantly between the two years of study with the highest peak during the first year $[F(1,8)=14.90 ; P=0.001]$ (Fig. 5). The population peaks were higher in the inter-cropped fields than in the mono-cropped fields in the first year of the study, but in the second year population peaks were higher in the monocropped fields $[F(1,8)=6.50 ; P=0.034]$ (Fig. 5). Population peaks in the fields were time-dependent and were not affected by cropping systems.

\section{Recruitment of new individuals}

We hypothesized that variation in the recruitment of $M$. natalensis is closely associated with varying conditions created in the environment through farming practices. During the 1999 noncropping season, land preparation methods and cropping system had no significant effects on the proportion of new individuals entering the trappable population $(P \leq 0.05)$. However, the proportions of new individuals differed significantly between months $[F(4,16=7.2991, P=0.0015)]$. Tukey HSD test showed that there were more individuals entering the trappable population during September $(P=0.008)$, October $(P=$ $0.001)$ and November $(P=0.008)$ than in July. This corresponded with increasing population trend (Fig. 6).

During the short rain season, there was a significant effect of ploughing on the proportion of new individuals 

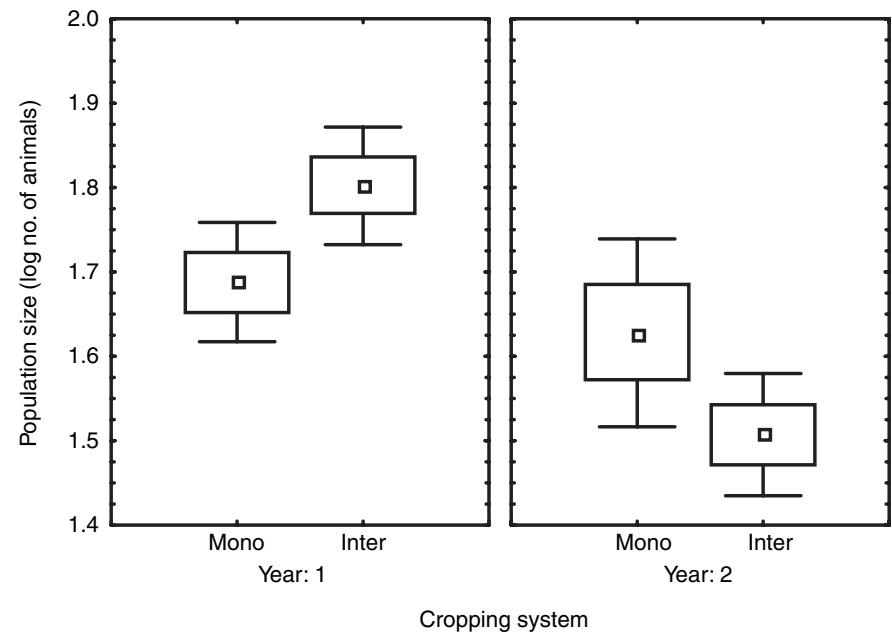

Cropping system
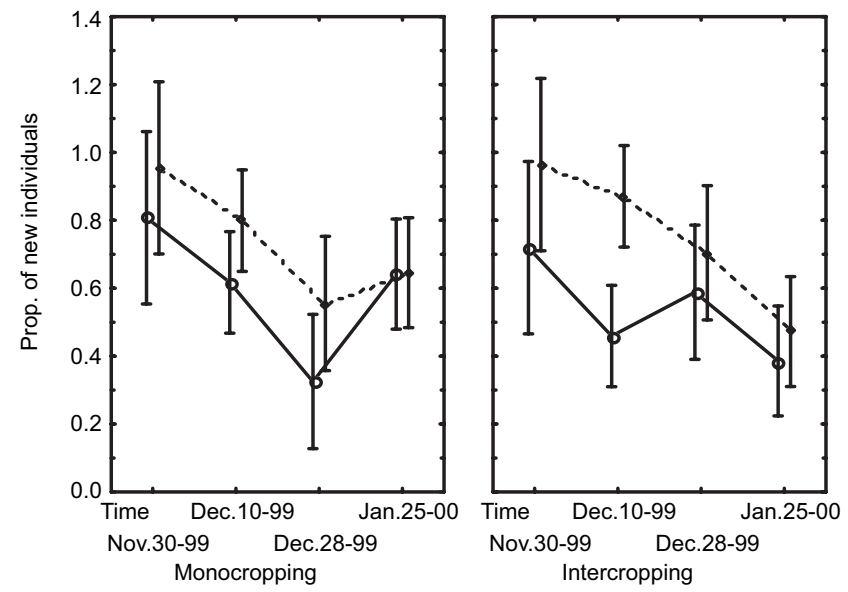

Fig 5 Actual rodent population peaks in different cropping systems during the study period $(P<0.05)$
Fig 6 Proportion of new individuals entering the trappable population at different time intervals during growing season of maize in the different treatments in the 1999 short rainy season $(P \leq 0.05)$. Nov.2-99 = Before ploughing, Nov.3099 = after ploughing, Dec.10-99 = After seed emergence, Dec.28-99 = At vegetative stage, Jan.25-00 = At maturity stage entering the trappable population at different stages of maize production (Table 1). Recruitment of new individuals was higher in the slash and burn field than in the tractor ploughed field $[F(1,4)=35.23 ; \quad P=0.004]$. Cropping system had no significant effect on recruitment of new individuals, but the effects on recruitment were timedependent [cropping system-time interaction, $F(3,12)=$ 4.22; $P=0.03$ ]. Figure 6 shows that before ploughing there were no significant differences in the proportion of newly recruited individuals. However, significant differences between the tractor and the slash and burn fields occurred after ploughing until the vegetative stage, when densities declined in all the fields. Cropping systems seemed to have a little effect on recruitment in the slash and burn
Table 1 Analysis of variance showing the proportion of new individuals entering the trappable population in fields subjected to different treatments during the short rainy season (1999)

\begin{tabular}{|c|c|c|c|c|c|c|}
\hline & \multicolumn{2}{|c|}{ Effect } & \multicolumn{2}{|c|}{ Error } & \multirow[b]{2}{*}{$F$} & \multirow[b]{2}{*}{$P$-level } \\
\hline & Df & MS & Df & MS & & \\
\hline Cropping system & 1 & 0.025 & 4 & 0.011 & 2.226 & 0.210 \\
\hline Ploughing & 1 & 0.401 & 4 & 0.011 & 35.229 & 0.004 \\
\hline Time & 3 & 0.121 & 12 & 0.006 & 19.539 & 0.000 \\
\hline System*ploughing & 1 & 0.029 & 4 & 0.011 & 2.533 & 0.187 \\
\hline System*time & 3 & 0.026 & 12 & 0.006 & 4.215 & 0.030 \\
\hline Ploughing*time & 3 & 0.017 & 12 & 0.006 & 2.788 & 0.086 \\
\hline $3 *$ Interaction & 3 & 0.016 & 12 & 0.006 & 2.543 & 0.105 \\
\hline
\end{tabular}

Significant at $P \leq 0.05$. 
fields. Interaction between ploughing and cropping system was not significant. During the long rainy season (2000), ploughing and cropping system had no significant effect on the proportion of new individuals entering the trappable population, but showed significant effects $(P \leq 0.05)$ with time.

\section{Discussion}

Rainfall (timing, duration and amount) has a strong influence on the population dynamics of rodents as it indirectly affects availability of resources. However, in the current study, population densities were significantly influenced by the land preparation methods and the mosaic nature of the surrounding fields. As only one species, M. natalensis, was considered in the analysis because of its abundance and dominance in the study area, there was no effect of trap type (Sherman live traps) in the trappability of the species in the experimental fields.

The immediate effect of slash and burn and tractor ploughing was a drastic drop in population size, but numbers increased fast again in the slash and burn fields after germination of maize seedlings and emergence of weeds. The increased population size was probably due to recolonization from the fallow land, but this is subject to further investigations. Although the density of rodents increased in both types of land preparation and cropping systems later in the season, this may not be of great importance in protecting the crop because the most susceptible crop stage would have passed.

Immediately after the slashing and burning, a decrease in population of M. natalensis in the fields occurred. Beck \& Vogl (1972) suggested that some of the mortality associated with fire might have been caused by predation. Burned areas are left open and therefore, the lack of cover improves accessibility to avian and mammalian predators (Motobu, 1978). Green \& Taylor (1975) did an experiment on habitat alteration by removing vegetation and found that $M$. natalensis was not affected by this trial. It was also observed in Kenya and Uganda that M. natalensis numbers remained unchanged immediately after burning or even increased sharply (Neal, 1970; Martin \& Dickson, 1985). However, observations in the current study show that after the sprouting and emergence of weed and crop seedlings, number of rodents increased. This suggests that recolonization of the fields by animals which probably emigrated during the fire occurred. However, it remains to be shown how the population will respond to slash and burn over large fields, which are not interspersed with fallow land, as was the case in the current study. With slash and burn over a large area it is also possible that some animals will be killed by the fire, thus the population would be reduced. However, a reduced population size, under favourable conditions, could lead into compensation in fecundity resulting to the population returning to its prefire density or higher, as has been observed after rodent poisoning (Zhang et al., 1999).

The findings of this study show that recruitment of new individuals was greater in the slash and burn than in the tractor ploughed fields, suggesting that more favourable conditions were created by slash and burn land preparation methods. There have been some suggestions that unburnt seeds on the ground attract rodents to such fields (Makundi et al., 1999). Therefore, it will be of interest to investigate this hypothesis and also the influence of germinating weed and crop seeds on recruitment of individuals and to establish whether there are specific cues that attract them to the new growth.

Burning of bush and crop residues in the fields is a common practice traditionally associated with shifting cultivation systems in developing countries (Norman, Quedraogo \& Newman, 1981). Among its advantages is the benefit in cattle raising areas where it stimulates the growth of early grasses. Also burning reduces the time required in clearing bush, an important consideration where labour is predominantly manual. It has been suggested that burning of plant stubble is a labour-saving strategy that also helps to reduce diapausing insects and weed seeds and lowers the levels of primary disease inoculum on plants and in the soil (Moreno, 1985). Janzen (1973) also reported destruction of insects' refugia through burning. With this knowledge in mind, it is also presumed by farmers that during burning rodents are killed by the fire as is the case with the arthropod pests. However, recently burned fields can be considered as disturbed habitats and therefore, the animals escape the fire by moving to unburnt areas (emigration) or remain safe in the burrows over the duration of the fire.

New vegetation presumably provides better nutrition for rodents and the requirements for breeding, growth and survival of young. Being an r-selected species (Leirs et al., 1997a), M. natalensis are perhaps better adapted to colonize newly burnt Savannah land in Sub-Saharan Africa, where fires are common at the end of the dry season, and immediately after the onset of the rains. Being a generalist in feeding habits (Leirs, Verhagen \& Verheyen, 1994), it is 
therefore better adapted for colonizing areas such as the slash and burn fields. This suggests that burning before the onset of rains and the subsequent sowing of seeds create favourable conditions for colonization by $M$. natalensis. It has been suggested that regenerating vegetation and availability of weed seeds on the ground create an attractive food resource for species such as M. natalensis (De Graaf, 1981).

Land preparation methods in the current study influenced recruitment and survival, which are some of the key factors in rodent population dynamics. It is obvious that in the slash and burn fields the population of rodents increased after the burn, and is probably due to immigration of new and old individuals. However, in the tractor ploughed fields, the drop in population density could be attributed to emigration and mortality. Earlier studies by Leirs et al. (1997b) indicated a quick decrease in the abundance of $M$. natalensis immediately after ploughing and planting, but also a sharp increase thereafter. The longterm effect is the lowering of the survival of M. natalensis in these fields. The importance of tractor ploughing in reducing rodent populations, particularly M. natalensis, is not well known by farmers in Tanzania, but it has been shown that ploughing reduces the population of some other species such as Cricetulus triton in cultivated fields in China (Zhang et al., 1999). Cropping systems had no significant influence on population dynamics. This further shows that the land preparation methods were more important in determining the population density of $M$. natalensis in the fields during the cropping seasons.

\section{Acknowledgements}

We wish to thank the SUA-VLIR Programme for the financial support for this study. The staff of the SUA Pest Management Center rendered valuable technical assistance and are cordially thanked.

\section{References}

BECK, A.M. \& VogL, R.J. (1972) Effect of spring burning on rodent populations in bush prairie savanna. J. Mammol. 53, 336-346. De GraAf, G. (1981) The Rodents of Southern Africa. Butterworths, Durban.

GreEn, M. \& TAYloR, K.D. (1975) Preliminary experiments in habitat alteration as a means of controlling field rodents in Kenya. In: Biocontrol of Rodents (Eds L. HANsSON and B. NiLSON), Ecol. Bull. 19, 175-282.
JANZEN, D.H. (1973) Tropical agro-ecosystems: these habitats are misunderstood by the temperate zone, mismanaged by the tropics. Science 182, 1212-1219.

Leirs, H., Verhagen, R. \& Verheyen, W. (1994) The basis of reproductive seasonality in Mastomys rats (Rodentia: Muridae). $J$ Trop. Ecol. 10, 55-66.

Leirs, H., Stenseth, N.C., Nichols, J.D., Hines, J.E., Verhagen, R. \& VERHEYEN, W. (1997a) Density-dependent and density independent factors regulate population dynamic of an Africa rodent. Nature 389, 176-180.

Leirs, H., Verhagen, R., Sabuni, C.A., Mwanjabe, P.S. \& Verheyen, W.N. (1997b) Spatial dynamics of Mastomys natalensis in a fieldfallow mosaic in Tanzania. Belg. J. Zool. 127(Suppl. 1), 29-38. MAKUNDI, R.H. (1999) Toward an Ecological approach for management of plague reservoirs and vectors in the Western Usambara Mountains in Tanzania, East Africa. In: Rodent Biology and Management (Eds Z.-B. ZHANG, L. Hinds, G. SingLETON and Z.-W. WANG). ACIAR Technical Reports no. 45, Canberra.

Makundi, R.H, Oguge, N.O. \& Mwanjabe, P.S. (1999) Rodent pest management in East Africa - an ecological approach. In: Ecologically-based Rodent Management (Eds G. Singleton, L. Hinds, H. LeIRS and Z. ZHANG). Australian Center For International Agricultural Research, Canberra, Australia.

MARTin, G.H.G. \& Dickson, N.M. (1985). Small mammal abundance in relation to microhabitat in a dry sub-humid grassland in Kenya. Afr. J. Ecol. 23, 223-234.

Massawe, A. W., Leirs, H., Rwamugira, W. P. \& Makundi, R. H. (2003) Effect of land preparation methods on spatial distribution of rodents in crop fields. In: Rats, Mice and People: Rodent Biology and Management (Eds G. R. Singleton, L. A. Hinds, C. J. KREBS and D. M. SPRATT). Australian Centre for International Agricultural Research, Canberra.

Mitan, P.P. (1990) Evaluation of control methods for rats in Philippines coconut plantation. In: Current Mammalogy, Vol. 2 (Ed. E. E. Genoways). Plenum Publication Corporation, New York.

Moreno, R.A. (1985) Plant pathology in the small farm context. Am. Rev. Phytopathol. 23, 491-512.

Мотовu, D.A. (1978) Effects of controlled slash burning on the mountain beaver (Aplodontia rufarufa). North. Sci. 52, 9299.

Mwanjabe, P.S. (1993) The role of weeds on population dynamics of Mastomys natalensis in Chunya (Lake Rukwa) valley. In: Economic Importance and Control of Rodents in Tanzania (Ed. R. S. MACHANGU). Workshop Proceedings, 6-8 July 1992. Sokoine University of Agriculture, Morogoro.

MүLLYмÄкI, A. (1989) Population dynamics of Mastomys natalensis (Smith) in relation to agricultural systems, incidence of damage and implications in control strategies. Final Report. DenmarkTanzania Rodent control Project, DANIDA Mission-Dar-es-Salaam, Tanzania.

NEAL, B.R. (1970) The habitat distribution and activity of a rodent population in Western Uganda, with a particular reference to the effects of burning. Rev. Zool. Bot. Afr. 81, 29-50. 
Norman, D.W., Quedraogo, I. \& Newman, M.D. (1981) Crop processes. In: Farm and Village Production Systems in the Semi-arid Tropics of West Africa: An Interpretive Review of Research (Eds D. W. Norman, M. D. NeWman and I. Quedraogo). ICRISAT Res. Bull. 1, 50-65.

TAYLOR, K.D. (1968) An outbreak of rats in agricultural areas of Kenya in 1962. East Afr. Agric. For. J. 34, 66-77.

White, G.C., ANDERson, D.R., BuRnham, K.P. \& OTIs, D.L. (1982) Capture-Recapture and Removal Methods for Sampling Closed

Populations. Los Alamos National Laboratory, Los Alamos, NM.
Zhang, Z., Chen, A., Ning, Z. \& Huang, X. (1999) Rodent pest management in agricultural ecosystem in China. In: Ecologically-based Rodent Management (Eds G. R. SingLETON, L. A. Hinds, H. LEIRS and Z. ZHIBIN). Aciar Monograph No. 59, Canberra.

(Manuscript accepted 13 October 2006)

doi: 10.1111/j.1365-2028.2006.00709.x 